\title{
Consent Issues in the Management of Acute Ischemic Stroke
}

\author{
AAN Position Statement
}

Justin A. Sattin, MD, Winston Chiong, MD, PhD, Richard J. Bonnie, JD, Matthew P. Kirschen, MD, PhD, and James A. Russell, DO, on behalf of the Ethics, Law, and Humanities Committee, a joint committee of the American Academy of Neurology, American Neurological Association, and Child Neurology Society

Neurology ${ }^{\circledR}$ 2022;98:73-79. doi:10.1212/WNL.0000000000013040

\author{
Correspondence \\ Dr. Sattin \\ sattin@neurology.wisc.edu
}

\begin{abstract}
This position statement briefly reviews the principle of informed consent, the elements of decisional capacity, and how acute stroke may affect this capacity. It further reviews the role of surrogate decision-making, including advance directives, next of kin, physician orders for life-sustaining treatment, and guardianship. In some cases of acute stroke in which the patient lacks decisional capacity and no advance directives or surrogates are available, consent to treatment may be presumed. The document describes the rationale for this position and various considerations regarding its application to IV thrombolysis, neuroendovascular intervention, decompressive craniectomy, and pediatric stroke. The document also reviews consent issues in acute stroke research.
\end{abstract}

\section{Introduction}

Despite recent advances in treatment and prevention, stroke remains the second leading cause of death worldwide and the fifth leading cause of death in the United States, with nearly 800,000 strokes occurring each year. There is a rapidly evolving repertoire of treatments that are highly effective in preserving neurologic function after stroke, but only if administered quickly, during a time when patients often lack decisional capacity and surrogate decision-makers may be unavailable. Whereas there are ethical issues surrounding many aspects of stroke prevention and treatment, ${ }^{1}$ this position statement, which replaces the American Academy of Neurology's 1999 position paper $^{2}$ as well as a 2011 policy statement, focuses specifically on issues of informed consent that arise in the context of acute ischemic stroke treatment.

\section{Informed Consent and Decisional Capacity}

\section{Elements of Informed Consent}

Elements of informed consent include the disclosure of relevant information, recommendation of a plan, and the patient's authorization (or refusal) of the recommended course of action in the absence of coercion. ${ }^{3}$ This framework presupposes that the patient has the capacity to understand and decide; such decisional capacity is commonly framed in 4 parts: ${ }^{4}$

1. Understanding - a grasp of the basic facts surrounding a decision, including the nature of the condition, the proposed intervention, and the alternatives, risks, and benefits thereof; understanding may be assessed by asking patients to rephrase provided information in their own words. 


\section{Glossary}

EFIC $=$ Exception From Informed Consent FDA = Food and Drug Administration; $\mathbf{m R S}=$ modified Rankin Scale; POLST = Physician Orders for Life-Sustaining Treatment.

2. Appreciation-recognition of how the provided information applies to one's own case; this may be assessed by asking patients to give a plausible explanation of why a proposed course of action will or will not benefit them.

3. Reasoning - this includes the ability to compare options and consistently infer the consequences of one's choices; it may be assessed by asking patients how each of the available options will affect their daily lives.

4. Choice-expressing a decision, which should be reasonably stable in the absence of new information.

\section{Stroke-Related Challenges to the Consent Process}

Obtaining informed consent in acute stroke can be encumbered by the sudden, unanticipated, onset of the inability to fulfill one or more of these elements, coupled with the necessity to make decisions rapidly about thrombolysis, thrombectomy, and other high-stakes interventions. For example, understanding of presented information is often impaired in patients with Wernicke aphasia; appreciation may be absent in patients with anosognosia and hemineglect, who do not recognize that they are neurologically impaired; reasoning, particularly about quantitative and probabilistic risks, can be diminished by prefrontal or parietal injury; and patients with Broca aphasia or those with reduced consciousness due to brainstem ischemia may be unable to consistently express a choice.

\section{Cultural Considerations}

In bioethical discourse, informed consent is rooted in the ethical principle of autonomy, which may be viewed more generally as an expression of respect for persons. ${ }^{5}$ Self-determination and informed consent have been affirmed as ethical requirements across cultural and national contexts, as in the World Medical Association Declaration of Lisbon on Rights of the Patient ${ }^{6}$ and in the Declaration of Helsinki. ${ }^{7}$ Medical decision-making in the United States largely emphasizes autonomy, but some cultural traditions within the United States and abroad place greater weight on considerations of community and solidarity. Decisional capacity should be assessed with particular care when such differences are observed, understanding that fully exploring, validating, and applying them to the informed consent process may not be possible in the timeconstrained acute stroke setting. In the context of interventions such as hemicraniectomy and research, where time constraints are often not as limiting, cultural perspectives may play a greater role.

\section{Surrogate Decision-making}

\section{Advance Directives}

When a patient loses decisional capacity, a measure of autonomy can be preserved if care can be directed by preferences previously expressed by the patient in an advance health care directive. There are 2 broad types of advance directives, although many patients' directives include elements of both. The first type of advance directive (often called a "living will" or "instruction directive") specifies particular interventions that patients anticipate that they would accept or reject. The instructions in these documents are often either overly specific or too vague, making it difficult to use them to arrive at treatment decisions in the context of acute stroke. For example, many living wills address end-of-life scenarios-often termed "terminal conditions"- but the documents may not adequately reflect patient preferences in relation to debilitating, but often nonfatal, conditions such as acute stroke. ${ }^{8}$

The second type of advance directive ("durable power of attorney for health care" or "proxy directive") appoints a surrogate decision-maker (in different states variously termed a health care proxy, agent, representative, or medical decision-maker) to make medically indicated decisions on the patient's behalf. These documents allow for greater flexibility and for decisions informed by patients' actual clinical situations, but many surrogates are inadequately prepared for their role in representing patients' wishes. ${ }^{9}$ For these reasons, the neurologist and other clinicians are often put in the position of guiding the patient's surrogate through the decision-making process:

1. Surrogate decision-makers' ethical imperative is to give priority to patient preferences expressed premorbidly, when patients retained decisional capacity, such as in an advance directive or a clear oral statement.

2. When no explicit statement of the patient's preferences exists, surrogates are expected to apply "substituted judgment," attempting to determine what the patient would have wanted, given their general knowledge of the patient's values and beliefs. Even when made in good faith, multiple studies have demonstrated that such judgments about patient wishes by family members ${ }^{10}$ and clinicians ${ }^{11}$ are imperfect.

3. When the patient's wishes are unknown, surrogate decision-makers and the clinicians counseling them attempt to arrive at treatment decisions based on the patient's "best interests"- often relying on a prediction of the patient's likely quality of life with and without the available treatments. One danger in such judgments is that healthy people tend to systematically underrate the quality of life of patients with chronic disabilities, such as those that are often sequelae of stroke. ${ }^{12}$

\section{Next of Kin}

If the patient has not executed an advance directive, or it is not available, some (but not all) states have enacted statutes 
authorizing a next of kin to make surrogate decisions for patients who lack decisional capacity. (The family members are hierarchically arranged, usually beginning with the patient's spouse, then proceeding to their adult children, parents, siblings, and so forth.) If no statutorily authorized next of kin is available, some state laws empower hospital ethics committees to designate a willing person sufficiently familiar with the patient's wishes and values to make a substituted judgment, thereby avoiding the need to seek judicial involvement.

\section{Physician Orders for Life-Sustaining Treatment}

Many, but not all, states have passed laws recognizing Physician Orders for Life-Sustaining Treatment (POLST; acronyms and terminology vary across states). ${ }^{13}$ Unlike advance directives, POLST are medical orders created by physicians, although in most states they are also signed by the patient (if the patient has capacity) or a legally recognized decision-maker (if the patient lacks capacity). The content of POLST forms varies by state, but they generally address life-prolonging treatments such as cardiopulmonary resuscitation, IV antibiotics, and artificial nutrition and hydration. In acute stroke, reperfusion therapies (discussed below) aim to preserve functional independence rather than prolong life, so the options designated in POLST forms do not directly apply to decisions about these interventions. However, for decisions regarding hemicraniectomy for malignant hemispheric stroke (also discussed below), a POLST order for "Full treatments" (i.e., "Attempt to sustain life by all medically effective means") could be action-guiding.

\section{Guardianship}

For patients without capacity who do not have advance directives (or whose designated surrogate decision-makers are unable or unfit to make decisions on their behalf), the court may appoint a guardian (in some states called a conservator or a conservator of the person). Unless guardianship happened to be in place already for other reasons, the time required to pursue such would generally be incompatible with the urgency of acute stroke treatments. For patients who are already under guardianship, neurologists should be aware that some states expressly limit the authority of the guardian to withhold or withdraw life-sustaining treatments. ${ }^{14}$ As above, acute reperfusion therapies are function- rather than life-preserving, but hemicraniectomy might indeed fall under the purview of guardianship laws of this type.

\section{Institutional Resources}

Most situations in acute ischemic stroke require emergent decision-making. When patients lack both decisional capacity and advance directives or surrogates, the treating physicians will have to make clinical decisions on their behalf; the following section reviews ethical considerations regarding various clinical scenarios. For clinical decisions that are less urgent (e.g., when considering hemicraniectomy within some hours), many institutions have ethics committees that can aid in decision-making for unrepresented patients.
Although advance directives have been endorsed by the Supreme Court of the United States in Cruzan ${ }^{15}$ and by Congress in the Patient Self-Determination Act, ${ }^{16}$ they are governed by state law and thus vary by jurisdiction, as do POLST and guardianship procedures. Neurologists should be familiar with the laws relevant to these entities in their jurisdictions of practice and, when appropriate, seek legal consultation regarding their application.

\section{Emergency Treatment for Acute Stroke}

What is the neurologist to do in an emergency situation when rapid treatment for acute stroke is indicated, the patient lacks decisional capacity, no determinative advance directive governs the situation, and no authorized surrogates are available? In these situations, interventions may be provided based on the ethical ${ }^{2,3}$ and common $1 \mathrm{w}^{17}$ presumption of consent; that is, the rationale that reasonable people would consent to treatment if they could be asked. Whereas this presumption of consent is most easily appreciated in life-threatening emergencies, the imminent risk of significant disability—not just death—also justifies emergent treatment in these circumstances. ${ }^{18,19}$ Empirical support for this conclusion has been borne out in multiple studies showing that patients consider severe stroke-related disability as undesirable as or worse than death. ${ }^{20,21}$ Furthermore, a general population study found that the desirability of thrombolysis for acute ischemic stroke is roughly equivalent to that of cardiopulmonary resuscitation in cardiac arrest, an imminently life-threatening situation in which the presumption of consent is generally accepted. $^{22,23}$

\section{Thrombolysis}

IV administration of alteplase (Activase; formerly known as tissue plasminogen activator) was the first acute stroke treatment demonstrated to improve patients' neurologic function. It remains first-line therapy, even for likely endovascular treatment candidates, for selected patients presenting within $3^{24}$ or $4.5^{25}$ hours from stroke onset or the time that the patient was last known to be well. When patients retain decision-making capacity (or surrogates are available), they should be quickly but clearly informed about:

1. The stroke diagnosis and rationale for thrombolytic therapy

2. The patient's prospects for achieving a good functional outcome with and without treatment

3. Risks of treatment, including intracerebral hemorrhage and angioedema

Alteplase treatment within the 3-hour window is approved by the Food and Drug Administration (FDA), whereas treatment of selected patients within the 4.5-hour window is scientifically recommended ${ }^{26}$ but remains off-label. The treating neurologist should discuss this, when possible, with the patient or surrogate. 
There are numerous contraindications to thrombolytic treatment. Some, such as intracranial hemorrhage, are absolute. Others, such as "minor" deficits, are considered relative contraindications because of uncertainty about their definitions (which neurologic deficits are too minor to warrant treatment?) or about the balance of risks and benefits in a particular circumstance (e.g., treatment in the 4.5-hour window in patients older than 80 years). A review of the scientific evidence behind the various IV thrombolytic contraindications has been published ${ }^{27}$ and can inform treatment decisions in cases where relative contraindications exist. With a cognitively intact patient or the help of a family member, the treating neurologist can engage in a careful discussion of individual risks and benefits of treatment in such cases. When the balance of these risks and benefits is uncertain, and the patient lacks decisional capacity and lacks a surrogate, then the neurologist should adhere more closely to guideline-based inclusion and exclusion criteria. ${ }^{26}$

Verbal consent (or refusal) to treatment should be obtained and documented in the medical record by the treating physician. Some institutions and jurisdictions, such as the Veterans Health Administration, ${ }^{28}$ require written consent for thrombolysis; acute stroke protocols at such facilities should therefore take into account the potential for treatment delays.

New approaches continue to be developed to improve patient selection and outcomes; recently reported innovations include the use of alternative medications ${ }^{29}$ or multimodal imaging in expanded time windows for selected patients. ${ }^{30,31}$ As clinical evidence and practice with respect to IV stroke treatment continue to evolve, neurologists will face more situations in which treatment decisions must be made for patients who lack capacity. When an appropriately designated surrogate decision-maker is present, neurologists should be prepared to engage them in a discussion of the risks and benefits of new interventions. When surrogates are not present, it may be reasonable to proceed with treatment on the presumption of consent when patients' cases fit extant inclusion/exclusion criteria, contraindications (particularly, absolute contraindications) are absent, and the overall balance of risks and benefits strongly favors intervention.

\section{Neuroendovascular Intervention}

In 2015, several randomized studies demonstrated the benefit of mechanical thrombectomy for large vessel occlusions in the anterior circulation. ${ }^{32}$ More recently, 2 additional studies have been published showing that selected patients stand to benefit up to 16-24 hours from stroke onset or from the time that the patient was last known to be well. $^{33,34}$ In cases of large hemispheric stroke for which endovascular therapy would be considered, patients are much more likely to be cognitively impaired. Moreover, when patients are evaluated in comprehensive stroke centers remote from their local communities, their families may be in transit or otherwise unavailable at the time a treatment decision needs to be made. Therefore, many of the ethical issues regarding IV thrombolysis are even more pressing in endovascular treatment. Patients who meet established criteria ${ }^{26}$ for endovascular therapy but who lack both decisional capacity and a surrogate decisionmaker should be treated on an emergency basis. The patient or surrogate should later be informed about what was done and how the time-sensitive circumstance precluded the usual consent process. The further outside of published criteria that a patient's condition falls, the less justified would be emergency treatment absent patient or surrogate consent.

\section{Decompressive Craniectomy}

Malignant brain swelling is a feared and potentially fatal complication of large-territory ischemic stroke. Cerebral edema can lead to compounding injury beyond the originally affected territory via mass effect, herniation, obstructive hydrocephalus, and intracranial hypertension. Decompressive craniectomy is often employed to interrupt this cascade and can be lifesaving. However, most patients in whom decompressive craniectomy is considered will be unable to consent to the procedure, as in both cerebral hemispheric infarction and cerebellar infarction the most reliable indicator of brain tissue swelling is decreased level of consciousness. ${ }^{35}$ Large left hemispheric strokes are also often accompanied by aphasia and large right hemispheric strokes are often accompanied by anosognosia, both of which also impair decisional capacity.

When patients with large-territory ischemic strokes are admitted to the hospital, the possibility of developing malignant edema should be anticipated and communicated to patients who retain decisional capacity (as may be the case in cerebellar lesions) or to their surrogates (as will typically be necessary for large hemispheric strokes that impair decisional capacity). Such discussions can prompt earlier consideration about the course of action that will best promote the patient's values. As with advance care planning, this may help to avoid hasty and emotionally fraught decisions in the setting of a patient's clinical decompensation.

Discussions with patients or their surrogates should be informed by the likely outcomes of the potential interventions. In malignant cerebellar edema, decompression via suboccipital craniectomy is generally beneficial, often preserving the patient's life and usually resulting in a modified Rankin Scale (mRS) score of 2 or less. ${ }^{36}$ Therefore, in counseling patients with large cerebellar infarcts (or their surrogates), suboccipital craniectomy for cerebellar edema can be generally recommended when necessary in the absence of surgical contraindications or other functionally limiting conditions. In the case of a patient lacking surrogate decision-makers, surgical treatment on the presumption of consent is often justified given the favorable balance or risks and benefits.

In malignant hemispheric edema due to middle cerebral or internal carotid territory infarctions, decompression via 
hemicraniectomy can be lifesaving while also leaving patients with significant functionally limiting deficits. In many cases, this effectively averts death in favor of survival with major dependency. In a pooled analysis of 3 trials in patients age 60 and below, hemicraniectomy was considered to be beneficial on the assumption that survival with an $\mathrm{mRS}$ score of 4 (moderately severe disability, unable to walk without assistance, and unable to attend to own bodily needs without assistance) was a favorable outcome. ${ }^{37}$ In a trial of patients over age 60 , no surviving patients had an mRS score of 2 or less and only $7 \%$ had an mRS score of $3 .^{38,39}$

Thus, decision-making is more difficult for malignant cerebral hemispheric edema, as (particularly for older patients) hemicraniectomy involves a tradeoff between mortality and major dependency. Prospectively, many people rate severe disability as undesirable as or worse than death ${ }^{20,21}$ and most people consider an mRS score of 3 to be the maximum acceptable outcome score. ${ }^{40-43}$ However, retrospectively, long-term survivors of hemicraniectomy, including older patients, reported acceptable quality of life and agreed with their treatment. ${ }^{44,45}$ This discrepancy may reflect "response shifts" in which patients recalibrate and reprioritize their assessments of health-related quality of life after stroke and other disabling events. ${ }^{46}$ In decisions concerning hemicraniectomy, it remains controversial whether the prospective or retrospective perspective should be given priority, and thus how clinicians should advise surrogates or proceed when surrogates are unavailable. This is a challenging decision that must be guided as much as possible by consideration of the patient's own health-related values. The patient's premorbid functional status and life expectancy may be informative. Surrogates and clinicians faced with such decisions may take some comfort in the observation that most patients do not retrospectively regret having undergone surgery, even when this results in major disability.

\section{Pediatric Stroke}

Acute arterial ischemic stroke occurs in children at a rate of 1.2-8/100,000 person-years and 1 per 2,500-4,000 live births for neonates. ${ }^{47}$ Children typically present later than adults; because of diagnostic challenges and a high rate of mimicking conditions, the median time to diagnosis is 24 hours from symptom onset. $^{48,49}$ Therapeutic options for stroke management are similar to those for adults, although there is a lack of data on efficacy and safety for children. This leads to challenges in counseling families about the risks and benefits of a potential therapy.

Many therapies, including alteplase and mechanical thrombectomy, are not FDA-approved in children and are used offlabel. Parents or legal guardians are the legally authorized decision-makers for children and are expected to use the best interest standard when making medical decisions for them. The time constraints of obtaining informed consent for acute stroke therapies make this process challenging, especially given the lack of data for these high-risk procedures.

To aid with this process, institutions should create acute stroke treatment protocols and involve the appropriately qualified clinicians, namely physicians with experience and expertise in treating children with stroke. In the absence of a strong body of empirical data, physicians should rely on these opinion-based institutional standards and published guidance documents ${ }^{50}$ to counsel families and treat children with acute strokes. Additional supportive data from well-designed trials are required before establishing standards for treatment with thrombolysis or thrombectomy for young children and for children whose stroke severity or time to treatment fall outside of established adult guidelines.

\section{Consent Issues in Acute Stroke Research}

Just as stroke-related deficits can interfere with patients' capacity to consent to medical treatment, the same deficits may render patients incapable of consenting to clinical research. While this poses ethical challenges, the inclusion of patients with impaired decisional capacity in research is itself an ethical priority. Limiting clinical trials only to patients able to consent for themselves would restrict the generalizability of research by excluding patients with more severe strokes. ${ }^{51,52}$ These are the patients for whom new therapies and improved systems of stroke care are most urgently needed.

In case of incapacity, few patients' advance directives include specific instructions about what types of research they would consent to in advance. As with state laws about advance directives in a purely clinical context, laws governing surrogate decision-making for clinical research vary by jurisdiction. Many states lack explicit provisions for surrogate research consent; the 2017 revised Common Rule clarifies that in these states, individuals empowered to make clinical care decisions for patients can also serve as surrogate decision-makers for research. ${ }^{53}$ Still, designated surrogate decision-makers may have more difficulty in extrapolating from the patient's known wishes and beliefs to decisions about clinical research than to decisions about medical treatment, leading to greater reluctance to enroll. ${ }^{54}$ Enrollment of patients generally cannot be justified purely by appeal to patients' "best interests," as clinical trials typically involve exposing participants to unproven interventions in the interest of producing generalizable knowledge. 55

In patients without decisional capacity who also lack available surrogates at the time when enrollment decisions must be made, US regulations recognize 2 conditions in which patients may be enrolled in research without the patient's or surrogate's consent. First, institutional review boards may waive the requirement of informed consent for research with minimal risks, generally defined as risks similar in magnitude and probability to those encountered in daily life. ${ }^{56}$ This threshold may be met by some systems-level interventions or qualitative studies of care delivery processes, but is unlikely to be met by physiologic interventions directed at reperfusion or neuroprotection. 
Second, investigators may apply to the US FDA for an Exception From Informed Consent (EFIC), introduced in 1996 to permit research involving human subjects in need of emergency interventions whose ability to consent is impaired due to life-threatening conditions. ${ }^{57}$ These exceptions involve additional safeguards that may add to the cost and difficulty of conducting clinical trials, such as the requirement for public disclosure and community consultation. Moreover, recent research has raised concerns about equitable burdens in research in EFIC trials, as African Americans are overrepresented in EFIC trials. ${ }^{58}$

Of note, while the requirement of informed consent has been described by some as the "rate-limiting step" of acute stroke trials, ${ }^{59}$ waivers of consent are not generally associated with more rapid trial recruitment for controlled trials of clinical therapies delivered in traditional settings. ${ }^{60}$ However, such waivers may be of value in enabling novel trial designs, particularly of systems-level studies addressing the speed and efficiency with which standard therapies are delivered.

\section{Conclusion}

Decision-making for acute stroke, which is often complex in itself, can be complicated by patients' lack of either decisional capacity or an advance directive offering guidance applicable to this usually unanticipated situation. In pediatric stroke, the patient will usually have a parent or other surrogate available; a common challenge is the paucity of clinical data to guide decisions. The Federal Common Rule, state law, and individual trial protocols all govern enrollment in clinical trials. The Table summarizes a basic approach to ethical decision-making in these situations; neurologists also need to be familiar with the relevant laws in their jurisdictions of practice.

Table Consent Guidance for Major Categories of Acute Ischemic Stroke Treatment

\begin{tabular}{|c|c|c|}
\hline Type of treatment & Example & Guidance \\
\hline $\begin{array}{l}\text { Generally accepted } \\
\text { treatment }\end{array}$ & $\begin{array}{l}\text { IV thrombolysis } \\
\text { fitting all inclusion/ } \\
\text { exclusion criteria }\end{array}$ & $\begin{array}{l}\text { Proceed with treatment on } \\
\text { the presumption of } \\
\text { consent, if necessary. }\end{array}$ \\
\hline $\begin{array}{l}\text { Treatments requiring } \\
\text { heightened } \\
\text { consideration of risk/ } \\
\text { benefit tradeoffs }\end{array}$ & $\begin{array}{l}\text { Endovascular } \\
\text { treatment for distal } \\
\text { vascular occlusions }\end{array}$ & $\begin{array}{l}\text { Consider how far from } \\
\text { published standards the } \\
\text { case falls; the decision } \\
\text { whether to proceed should } \\
\text { be informed by how closely } \\
\text { the facts of the case match } \\
\text { current guidelines. }\end{array}$ \\
\hline $\begin{array}{l}\text { Treatments for which } \\
\text { evidence is lacking }\end{array}$ & Pediatric stroke & $\begin{array}{l}\text { Work with institutional } \\
\text { stakeholders to develop } \\
\text { local treatment protocols. }\end{array}$ \\
\hline $\begin{array}{l}\text { Investigational } \\
\text { treatment }\end{array}$ & $\begin{array}{l}\text { Enrollment in an } \\
\text { acute treatment } \\
\text { trial }\end{array}$ & $\begin{array}{l}\text { Laws regarding surrogate } \\
\text { consent vary by state, and } \\
\text { research protocols vary as } \\
\text { well. The Federal Common } \\
\text { Rule does allow lawful } \\
\text { surrogates to consent. }\end{array}$ \\
\hline
\end{tabular}

\section{Acknowledgment}

The authors thank the members of the Ethics, Law, and Humanities Committee and other experts who contributed to this manuscript by reviewing and offering suggestions, including Gabrielle deVeber, MSc, MD (Senior Scientist, Child Health Evaluative Sciences, The Hospital for Sick Children, Toronto, on behalf of the Child Neurology Society); Larry B. Goldstein, MD (Professor and Chair of Neurology, University of Kentucky); Lori Jordan, $\mathrm{MD}, \mathrm{PhD}$ (Director, Pediatric Stroke Program, Vanderbilt University Medical Center, on behalf of the Child Neurology Society); and Barney J. Stern, MD (Professor of Neurology, Johns Hopkins University); as well as Sarah Bird Nelson, JD (Associate Counsel, American Academy of Neurology) for her support in this project and for her longstanding commitment to the Ethics, Law, and Humanities Committee.

\section{Study Funding}

The authors report no targeted funding.

\section{Disclosure}

The authors report no disclosures relevant to the manuscript. Go to Neurology.org/N for full disclosures.

\section{Publication History}

Received by Neurology June 16, 2021. Accepted in final form October 25, 2021.

\section{Appendix Authors}

\begin{tabular}{lll}
\hline Name & Location & Contribution \\
\hline $\begin{array}{l}\text { Justin A. } \\
\text { Sattin, MD }\end{array}$ & $\begin{array}{l}\text { Department of Neurology, } \\
\text { University of Wisconsin, } \\
\text { Madison }\end{array}$ & $\begin{array}{l}\text { Drafting/revision of the } \\
\text { manuscript for content, } \\
\text { including medical writing for } \\
\text { content; study concept or } \\
\text { design }\end{array}$ \\
$\begin{array}{l}\text { Winston } \\
\text { Chiong, MD, } \\
\text { PhD }\end{array}$ & $\begin{array}{l}\text { Department of Neurology, } \\
\text { Francisco }\end{array}$ & $\begin{array}{l}\text { Drafting/revision of the } \\
\text { manuscript for content, } \\
\text { including medical writing for } \\
\text { content; study concept or } \\
\text { design }\end{array}$ \\
& &
\end{tabular}

Richard J. Institute of Law, Psychiatry Drafting/revision of the Bonnie, JD and Public Policy, University manuscript for content, of Virginia School of Law, including medical writing for Charlottesville content; study concept or design

\begin{tabular}{|c|c|c|}
\hline $\begin{array}{l}\text { Matthew P. } \\
\text { Kirschen, } \\
\text { MD, PhD }\end{array}$ & $\begin{array}{l}\text { Department of } \\
\text { Anesthesiology and Critical } \\
\text { Care Medicine, University of } \\
\text { Pennsylvania, Philadelphia }\end{array}$ & $\begin{array}{l}\text { Drafting/revision of the } \\
\text { manuscript for content, } \\
\text { including medical writing for } \\
\text { content; study concept or } \\
\text { design }\end{array}$ \\
\hline $\begin{array}{l}\text { James A. } \\
\text { Russell, DO }\end{array}$ & $\begin{array}{l}\text { Department of Neurology, } \\
\text { Lahey Hospital and Medical } \\
\text { Center, Burlington, MA }\end{array}$ & $\begin{array}{l}\text { Drafting/revision of the } \\
\text { manuscript for content, } \\
\text { including medical writing for } \\
\text { content; study concept or } \\
\text { design }\end{array}$ \\
\hline
\end{tabular}

\section{References}

1. Wheeler NC, Murali S, Sattin JA. Ethical issues in vascular neurology. Semin Neurol. 2018;38(5):515-521. 
2. Consent issues in the management of cerebrovascular diseases: a position paper of the American Academy of Neurology Ethics and Humanities Subcommittee. Neurology. 1999;53(1):9-11.

3. Beauchamp TL, Childress JF. Principles of Biomedical Ethics, 7th ed. Oxford University Press; 2013. Accessed January 5, 2019. worldcat.org/title/principles-of-biomedicalethics/oclc/827736605?referer=di\&ht=edition

4. Appelbaum PS, Grisso T. Assessing patients' capacities to consent to treatment. N Engl J Med. 1988;319(25):1635-1638.

5. Grady C. Enduring and emerging challenges of informed consent. N Engl J Med. 2015 372(9):855-862

6. World Medical Association. WMA Declaration of Lisbon on the Rights of the Patient. August 7, 2018. Accessed September 1, 2021. https://www.wma.net/policies-post/ wma-declaration-of-lisbon-on-the-rights-of-the-patient/

7. World Medical Association. World Medical Association Declaration of Helsinki Ethical Principles for Medical Research Involving Human Subjects. JAMA. 2013; 310(20):2191-2194.

8. Winter L, Parks SM, Diamond JJ. Ask a different question, get a different answer: why living wills are poor guides to care preferences at the end of life. J Palliat Med.2010; 13(5):567-572.

9. Institute of Medicine. Dying in America: Improving Quality and Honoring Individual Preferences Near the End of Life. Washington, DC: The National Academies Press. 2015.

10. Fried TR, Zenoni M, Iannone L, O’Leary J, Fenton BT. Engagement in advance care planning and surrogates' knowledge of patients' treatment goals. J Am Geriatr Soc. 2017;65(8):1712-1718

11. Downey L, Au DH, Curtis JR, Engelberg RA. Life-sustaining treatment preferences: matches and mismatches between patients' preferences and clinicians' perceptions. J Pain Symptom Manage. 2013;46(1):9-19.

12. Amundson R. Quality of life, disability, and hedonic psychology. J Theory Soc Behav. 2010;40(4):374-392.

13. Meier DE, Beresford L. POLST offers next stage in honoring patient preferences. J Palliat Med. 2009;12(4):291-295.

14. Spahn v. Eisenberg, 210 Wis. 2d 557, 563 N.W. 2d 485 (1997)

15. Cruzan v. Director, MDH, 497U.S. 261 (1990)

16. The patient Self-determination Act. Pub. L. No. 101-508, \$\$4206 \& 4751, 104 Stat. 1388 (codified in 42 USC \$S 1395cc[f], 1396a[w] [1994]).

17. Berg JW, Appelbaum PS, Lidz CW, Parker LS. Informed Consent: Legal Theory and Clinical Practice. 2nd ed. Oxford University Press; 2001.

18. Cunningham v. Yankton Clinic, P.A., 262 N.W.2d 508 (S.D. 1978)

19. Hondroulis v. Schumacher, 546 So. 2d 466 (La. 1989).

20. Hanger HC, Fogarty B, Wilkinson TJ, Sainsbury R. Stroke patients' views on stroke outcomes: death versus disability. Clin Rehabil. 2000;14(4):417-424.

21. Solomon NA, Glick HA, Russo CJ, Lee J, Schulman KA. Patient preferences for stroke outcomes. Stroke. 1994;25(9):1721-1725.

22. Chiong W, Kim AS, Huang IA, Farahany NA, Josephson SA. Testing the presumption of consent to emergency treatment for acute ischemic stroke. JAMA. 2014;311(16): 1689-1691.

23. Chiong W, Kim AS, Huang IA, Farahany NA, Josephson SA. Inability to consent does not diminish the desirability of stroke thrombolysis. Ann Neurol. 2014;76(2):296-304.

24. National Institute of Neurological Disorders and Stroke rt-PA Stroke Study Group. Tissue plasminogen activator for acute ischemic stroke. N Engl J Med. 1995;333(24): 1581-1587.

25. Hacke W, Kaste M, Bluhmki E, et al. Thrombolysis with alteplase 3 to 4.5 hours after acute ischemic stroke. N Engl J Med. 2008;359(13):1317-1329.

26. Powers WJ, Rabinstein AA, Ackerson T, et al. Guidelines for the early management of patients with acute ischemic stroke: 2019 update to the 2018 guidelines for the early management of acute ischemic stroke: a guideline for healthcare professionals from the American Heart Association/American Stroke Association. Stroke. 2019;50(12): E344-E418.

27. Demaerschalk BM, Kleindorfer DO, Adeoye OM, et al Scientific rationale for the inclusion and exclusion criteria for intravenous alteplase in acute ischemic stroke. Stroke. 2016;47(2):581-641.

28. Dept. of Veterans Affairs; Veterans Health Administration. Informed Consent for Clinical Treatments and Procedures. VHA Handbook 1004.01(5). August 14, 2009; Amended September 17, 2021. Accessed January 21, 2019. https://www.va.gov/ vhapublications/ViewPublication.asp?pub ID $=2055$.

29. Burgos AM, Saver JL. Evidence that tenecteplase is noninferior to alteplase for acute ischemic stroke. Stroke. 2019;50(8):2156-2162.

30. Thomalla G, Simonsen CZ, Boutitie F, et al. MRI-guided thrombolysis for stroke with unknown time of onset. N Engl J Med. 2018;379(7):611-622.

31. Ma H, Campbell BCV, Parsons MW, et al. Thrombolysis guided by perfusion imaging up to 9 hours after onset of stroke. N Engl J Med. 2019;380(19):1795-1803.
32. Powers WJ, Derdeyn CP, Biller J, et al 2015 American Heart Association/American Stroke Association focused update of the 2013 guidelines for the early management of patients with acute ischemic stroke regarding endovascular treatment. Stroke. 2015; 46(10):3020-3035

33. Albers GW, Marks MP, Kemp S, et al. Thrombectomy for stroke at 6 to 16 hours with selection by perfusion imaging. N Engl J Med. 2018;378(8):708-718.

34. Nogueira RG, Jadhav AP, Haussen DC, et al. Thrombectomy 6 to 24 hours after stroke with a mismatch between deficit and infarct. N Engl J Med. 2018;378(1):11-21.

35. Wijdicks EFM, Sheth KN, Carter BS, et al Recommendations for the management of cerebral and cerebellar infarction with swelling. Stroke. 2014;45(4):1222-1238.

36. Jauss M, Krieger D, Hornig C, Schramm J, Busse O. Surgical and medical management of patients with massive cerebellar infarctions: results of the German-Austrian Cerebellar Infarction Study. J Neurol. 1999;246(4):257-264.

37. Vahedi K, Hofmeijer J, Juettler E, et al. Early decompressive surgery in malignan infarction of the middle cerebral artery: a pooled analysis of three randomised controlled trials. Lancet Neurol. 2007;6(3):215-222.

38. Jüttler E, Unterberg A, Woitzik J, et al. Hemicraniectomy in older patients with extensive middle-cerebral-artery stroke. N Engl J Med. 2014;370(12):1091-1100.

39. Ropper AH. Hemicraniectomy: to halve or halve not. N Engl J Med. 2014;370(12): 1159-1160.

40. Honeybul S, Ho KM, Blacker DW. ORACLE stroke study: opinion regarding acceptable outcome following decompressive hemicraniectomy for ischemic stroke. Neurosurgery. 2016;79(2):231-236

41. Olivecrona M, Honeybul S. A study of the opinions of Swedish healthcare personnel regarding acceptable outcome following decompressive hemicraniectomy for ischaemic stroke. Acta Neurochir. 2018;160(1):95-101.

42. Neugebauer H, Malakou F, Uttner I, Köpke M, Jüttler E. IGNITE study group (initiative of German NeuroIntensive trial engagement): attitudes of nurses toward disability and treatment in space-occupying middle cerebral artery stroke. Neurocrit Care. 2019;30(1):132-138.

43. Kim BJ, Hong YR, Han Y, Hwang YH, Ohk B, Park J. Age-dependent attitudes of ischemic patients toward disability after decompressive hemicraniectomy for malignant middle cerebral artery infarction. World Neurosurg. 2018;114:e51-e59.

44. Ragoschke-Schumm A, Junk C, Lesmeister M, et al Retrospective consent to hemicraniectomy after malignant stroke among the elderly, despite impaired functional outcome. Cerebrovasc Dis. 2015;40(5-6):286-292.

45. Das S, Mitchell P, Ross N, Whitfield PC. Decompressive hemicraniectomy in the treatment of malignant middle cerebral artery infarction: a meta-analysis. World Neurosurg. 2019;123:8-16

46. Barclay R, Tate RB. Response shift recalibration and reprioritization in health-related quality of life was identified prospectively in older men with and without stroke. J Clin Epidemiol. 2014;67(5):500-507.

47. deVeber GA, Kirton A, Booth FA, et al. Epidemiology and outcomes of arterial ischemic stroke in children: the Canadian Pediatric Ischemic Stroke Registry. Pediatr Neurol. 2017;69:58-70.

48. Srinivasan J, Miller SP, Phan TG, Mackay MT. Delayed recognition of initial stroke in children: need for increased awareness. Pediatrics. 2009; 124(2):e227-34

49. Shellhaas RA, Smith SE, O'Tool E, Licht DJ, Ichord RN. Mimics of childhood stroke: characteristics of a prospective cohort. Pediatrics. 2006;118(2):704-709.

50. Ferriero DM, Fullerton HJ, Bernard TJ, et al. Management of stroke in neonates and children: a scientific statement from the American Heart Association/American Stroke Association. Stroke. 2019;50(3):E51-E96.

51. Flaherty ML, Karlawish J, Khoury JC, Kleindorfer D, Woo D, Broderick JP. How important is surrogate consent for stroke research? Neurology. 2008;71(20):1566-1571

52. Kane I, Lindley R, Lewis S, Sandercock P. IST-3 collaborative group. Impact of stroke syndrome and stroke severity on the process of consent in the third international stroke trial. Cerebrovasc Dis. 2006;21(5-6):348-352.

53. 82 CFR $\$ 7149$ (III) (E) (4)(2017)

54. Demarquay G, Derex L, Nighoghossian N, et al. Ethical issues of informed consent in acute stroke. Analysis of the modalities of consent in 56 patients enrolled in urgent therapeutic trials. Cerebrovasc Dis. 2005;19(2):65-68.

55. Chiong W. The real problem with equipoise. Am J Bioeth. 2006;6(4):37-47.

56. 45 CFR $\$ 46.102(\mathrm{I})$

57. $21 \mathrm{CFR} \$ 50.24$

58. Feldman WB, Hey SP, Kesselheim AS. A systematic review of the food and drug administration's "exception from informed consent" pathway. Health Aff. 2018; 37(10):1605-1614

59. Rose DZ, Kasner SE. Informed consent: the rate-limiting step in acute stroke trials. Front Neurol. 2011;2:65.

60. Feldman WB, Kim AS, Josephson SA, Lowenstein DH, Chiong W. Effect of waivers of consent on recruitment in acute stroke trials: a systematic review. Neurology. 2016 ; 86(16):1543-1551. 


\section{Neurology}

\section{Consent Issues in the Management of Acute Ischemic Stroke: AAN Position Statement}

Justin A. Sattin, Winston Chiong, Richard J. Bonnie, et al. Neurology 2022;98;73-79

DOI 10.1212/WNL.0000000000013040

This information is current as of January 10, 2022

\section{Updated Information \& Services}

References

Subspecialty Collections

Permissions \& Licensing

Reprints including high resolution figures, can be found at: http://n.neurology.org/content/98/2/73.full

This article cites 47 articles, 4 of which you can access for free at: http://n.neurology.org/content/98/2/73.full\#ref-list-1

This article, along with others on similar topics, appears in the following collection(s):

All Cerebrovascular disease/Stroke

http://n.neurology.org/cgi/collection/all_cerebrovascular_disease_strok e

Critical care

http://n.neurology.org/cgi/collection/critical_care

Cross-cultural care

http://n.neurology.org/cgi/collection/cross_cultural_care

Professional conduct and ethics

http://n.neurology.org/cgi/collection/professional_conduct_and_ethics

Information about reproducing this article in parts (figures,tables) or in its entirety can be found online at:

http://www.neurology.org/about/about_the_journal\#permissions

Information about ordering reprints can be found online:

http://n.neurology.org/subscribers/advertise

Neurology ${ }^{\circledR}$ is the official journal of the American Academy of Neurology. Published continuously since 1951 , it is now a weekly with 48 issues per year. Copyright @ 2022 American Academy of Neurology. All rights reserved. Print ISSN: 0028-3878. Online ISSN: 1526-632X.

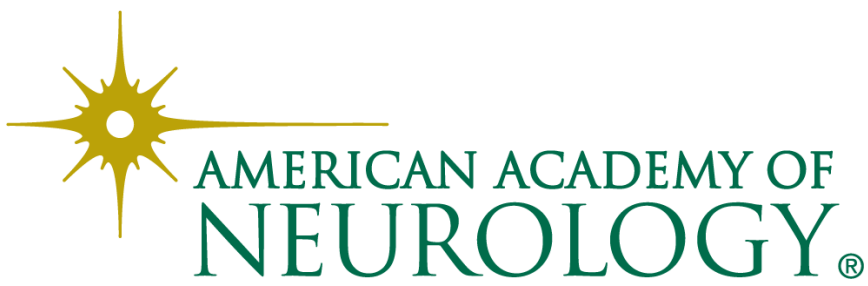

